\title{
Energetic and exergetic investigation of a parabolic trough collector with internal fins operating with carbon dioxide
}

\author{
Evangelos Bellos $^{1}$ (D) Christos Tzivanidis $^{1} \cdot$ Ilias Daniil $^{1}$
}

Received: 10 November 2016/ Accepted: 6 February 2017/Published online: 15 February 2017

(C) The Author(s) 2017. This article is published with open access at Springerlink.com

\begin{abstract}
The objective of this study is to determine the energetic and exergetic enhancement of parabolic trough collector with internal fins in the absorber. Carbon dioxide is the examined working fluid to investigate the performance of the system in high temperature levels. In the first part of this study, the impact of the mass flow rate on the collector performance is analyzed and finally $0.20 \mathrm{~kg} / \mathrm{s}$ is selected as the most appropriate mass flow rate exergetically. In the second part, the impact of internal fins on the system performance is investigated for operation with the optimum mass flow rate. More specifically, the absorber without fins is compared with three different fins with lengths 5, 10 and $15 \mathrm{~mm}$. The final results prove that the higher fin length increases the thermal performance, while the optimum fin length exergetically is $10 \mathrm{~mm}$ with $45.95 \%$ exergetic efficiency when the inlet temperature is equal to $400{ }^{\circ} \mathrm{C}$. The impact of the pressure losses along the collector is taken into account in the exergetic efficiency, which is the best index for evaluating solar collectors operating with gases. The analysis is performed with Solidworks Flow Simulation, a powerful tool which allows the simultaneous thermal and optical analysis.
\end{abstract}

Evangelos Bellos

bellose@central.ntua.gr

$\triangle$ Ilias Daniil

iliasdan93@gmail.com

Christos Tzivanidis

ctzivan@central.ntua.gr

1 Thermal Department, School of Mechanical Engineering,

National Technical University of Athens, Heroon

Polytehniou 9, Zografou, 15773 Athens, Greece
Keywords Parabolic trough collector - Carbon dioxide . Exergetic analysis - Thermal performance - Fins

\section{List of symbols}

\section{Variables}

A Area $\left(\mathrm{m}^{2}\right)$

C Concentration ratio (-)

$c_{\mathrm{p}} \quad$ Specific heat capacity under constant pressure (J/ $\mathrm{kg} \mathrm{K}$ )

$D \quad$ Diameter (mm)

E Exergy flow (W)

$f \quad$ Focal length (mm)

$G_{\mathrm{b}} \quad$ Solar beam radiation $\left(\mathrm{W} / \mathrm{m}^{2}\right)$

$h_{\text {out }}$ Convection coefficient between cover and ambient $\left(\mathrm{W} / \mathrm{m}^{2} \mathrm{~K}\right)$

$L \quad$ Tube length $(\mathrm{mm})$

$m \quad$ Mass flow rate $(\mathrm{kg} / \mathrm{s})$

$Q \quad$ Heat (W)

$R \quad$ Gas constant $(\mathrm{J} / \mathrm{kg} \mathrm{K})$

$r$ Concentrator reflectance (-)

$t \quad$ Fin length (mm)

$T$ Temperature $\left({ }^{\circ} \mathrm{C}\right)$

$W \quad$ Width (mm)

\section{Greek symbols}

$\alpha \quad$ Absorber absorbance (-)

$\varepsilon \quad$ Emittance (-)

$\Delta P$ Pressure drop $(\mathrm{kPa})$

$\eta \quad$ Efficiency (-)

$\tau \quad$ Cover transmittance $(-)$

\section{Subscripts and superscripts}

a Aperture 


$\begin{array}{ll}\text { am } & \text { Ambient } \\ \text { c } & \text { Cover } \\ \text { ci } & \text { Inner cover } \\ \text { co } & \text { Outer cover } \\ \text { ex } & \text { Exergetic } \\ \text { fm } & \text { Mean fluid } \\ \text { in } & \text { Inlet } \\ \text { opt } & \text { Optical } \\ \text { out } & \text { Outlet } \\ \text { r } & \text { Receiver } \\ \text { ri } & \text { Inner receiver } \\ \text { ro } & \text { Outer receiver } \\ \text { s } & \text { Solar } \\ \text { sun } & \text { Sun } \\ \text { th } & \text { Thermal } \\ \text { u } & \text { Useful }\end{array}$

Abbreviations

PTC Parabolic trough collector

\section{Introduction}

The increasing rate of the worldwide energy use is one of the most crucial threats of the recent years due to fossil fuel depletion [1], greenhouse gases emissions [2] and the population increase. Renewable energy sources [3, 4] as solar, wind, geothermal and hydropower can give sustainable solutions in the previous energy problems. Among them, solar energy is the most promising energy source, because it can be converted either to electricity by photovoltaics or concentrating power plants, or to thermal energy by solar thermal collectors (flat or concentrating) [5, 6]. Parabolic trough collectors (PTC) is the most mature technology for producing heat in medium and high temperature levels and this has been applied in a great number of applications up today [7].

The use of PTC in concentrating power plants, in industrial processes, in hydrogen production and in other similar high temperature applications is more and more usual the last years [8]. However, the conventional working fluids such as water, thermal oils and molten salts cannot operate in high temperature levels. Thus, a lot of interest has been given in the use of gas working fluids in PTC, as air, nitrogen, helium and carbon dioxide. These gases can be used at temperature levels close to $500-600{ }^{\circ} \mathrm{C}$ and up to $1000{ }^{\circ} \mathrm{C}$ in some cases. Carbon dioxide is among the most efficient working fluids according to the literature studies. In a recent analysis, Bellos et al. [9] examined six gas working fluids (air, nitrogen, carbon dioxide, helium, argon and neon) exergetically and finally carbon dioxide was proved to be the most efficient working fluid in high temperature levels. Cipollone et al. [10] examined air and carbon dioxide as possible working fluids in a discrete Ericsson cycle and they finally proved that the use of carbon dioxide leads to higher performance. Carbon dioxide was found to be more efficient than nitrogen and ammonia for concentrating power plants in the study of Islam et al. [11]. Moreover, Muñoz-Anton et al. [12] stated that carbon dioxide is able to be used for applications with temperature levels close to $500{ }^{\circ} \mathrm{C}$ with satisfying results. Al-Sulaiman and Atif [13] examined the use of carbon dioxide in supercritical Brayton cycles coupled with solar tower technology and Coco-Enríquez et al. [14] with parabolic trough collectors.

On the other hand, a lot of research has been focused on the improvements of the existing PTC in order their thermal performance to be enhanced. The basic idea is to increase the heat transfer rate from the absorber to working fluid, creating lower temperature levels on the absorber and consequently leading to higher thermal efficiency. Many techniques have been applied as the use of flow inserts, rough inner surfaces, internal fins and giving rotation in the flow [15]. The majority of the literature studies have tested various similar ideas for operation with thermal oils. Mwesigye et al. examined the utilization of wall-detached twisted tape inserts [16] and the use of centrally placed perforated plate inserts [17] in parabolic trough collectors with thermal oil. In the first case, the enhancement was about $10 \%$ while in the second was up to $8 \%$. Moreover, the use of various inserts in the flow as conical nozzles, conical rings, V-nozzles and screw-tapes [18, 19] are usually found in the literature. Munoz and Abanades with an interesting study [20] proved that the use of internal fins in the PTC is able to enhance the useful output approximately $2 \%$; an interesting enhancement with importance in application as the electricity production.

There are also some interesting studies where geometric improvements have been applied in parabolic collectors operating with gas working fluids. Kasperski and Nems [21] investigated multiple-fin arrays to enhance the thermal performance of parabolic trough collectors operating with air and they proved performance increase close to $14 \%$. In another interesting study, Too and Benito [22] examined dimpled tubular absorbers and inserts. They investigated air, helium and carbon dioxide and finally they noticed that carbon dioxide and helium are promising gases for carrying heat.

As it is obvious for the literature review, the use of gas working fluids and the geometrical modifications in the absorbers can lead to efficiency enhancement, especially in high temperature levels. Up to this time, there is lack of studies focused on the performance enhancements of PTC operating with the most promising working gas, the carbon dioxide. This study examines the use of internal fins in the absorber of PTC for operation with carbon dioxide. The 
analysis is performed in energetic and exergetic terms to take into account the pressure losses by the existence of fins. The fin length is examined parametrically to determine the optimum fin for the examined case. The final results can be used for estimating the performance enhancement by using internal fins for operation with carbon dioxide. The analysis is performed with Solidworks Flow Simulation, a powerful tool which combines simultaneous optical and thermal analysis features.

\section{PTC modeling}

In this section, the examined solar collector and the methodology of this work are presented. Section "The examined PTC module" is devoted for the description of the selected PTC module and the main dimensions of it are given. Section "Mathematical background" includes the basic mathematical background for the energetic and exergetic assessment of the examined system. Details about the developed model in Solidworks Flow Simulation are given in section "Analysis in Solidworks Flow Simulation" and finally section "Validation of the results" includes the comparison of the developed model with literature results.

\section{The examined PTC module}

In this study, a commercial parabolic trough collector is selected to be examined. More specifically, Eurotrough ET-150 is the analyzed PTC and it has been used in numerous applications and studies. Figure 1 illustrates the collector in its longitudinal and transversal side. The main parts of the PTC are the evacuated tube collector and the linear parabolic reflector. In real applications, many modules as this are located in series and usually many parallel series are used. Table 1 includes the main geometrical parameters of the examined PTC. The concentration ratio of this collector is about 26.37, the module aperture is $69.6 \mathrm{~m}^{2}$, the collector length is $12 \mathrm{~m}$ and the outer diameter of the absorber is $70 \mathrm{~mm}$. Moreover, the basic simulation parameters of this study are included in this table. The solar beam irradiation is selected to be $1000 \mathrm{~W} / \mathrm{m}^{2}$, the ambient temperature $293 \mathrm{~K}$ and the heat convection coefficient between cover and ambient is selected at $10 \mathrm{~W} /$ $\mathrm{m}^{2} \mathrm{~K}$.

In the present work, the usual smooth tubular absorber is compared with tubular absorbers with internal fins. Eight longitudinal internal fins are selected to be used and three different fin lengths are examined. More specifically, 5, 10 and $15 \mathrm{~mm}$ are the selected fin lengths that are investigated and the objective of this analysis is to determine how the length of them influences on the collector performance. In all the cases, the thickness of the examined fins is equal to $2 \mathrm{~mm}$ and the fins are located along the absorber tube. Figure 2 depicts the cross sections of the examined absorbers designed on Solidworks.

\section{Mathematical background}

The objective of this subsection is to present the basic mathematical background of the examined system. Equations about the thermal and the exergetic performance of the collector are given in order to determine how the results of the simulation tool are evaluated.
Fig. 1 The examined PTC module. a The longitudinal side of the collector. $\mathbf{b}$ The transversal side of the collector

\section{(a) Longitudinal side}

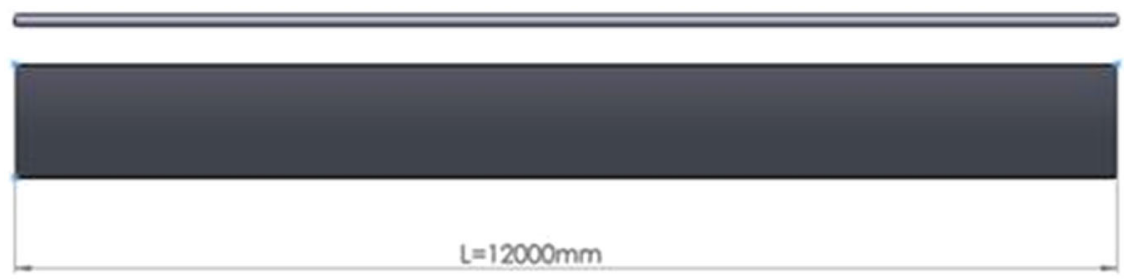

(b) Transversal side

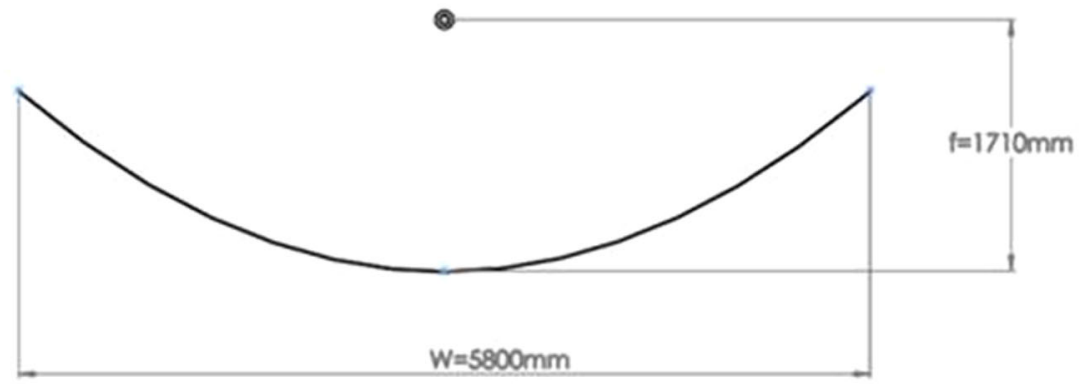


Table 1 Parameters for the examined model and the simulation

\begin{tabular}{llll}
\hline Simulation parameters & Values & Model dimensions & Values \\
\hline$\varepsilon_{\mathrm{r}}$ & 0.095 & $W$ & $5.8 \mathrm{~m}$ \\
$\varepsilon_{\mathrm{c}}$ & 0.88 & $L$ & $12 \mathrm{~m}$ \\
$G_{\mathrm{b}}$ & $1000 \mathrm{~W} / \mathrm{m}^{2}$ & $f$ & $1.71 \mathrm{~m}$ \\
$r$ & 0.93 & $A_{\text {a }}$ & $69.6 \mathrm{~m}^{2}$ \\
$\alpha$ & 0.92 & $C$ & 26.37 \\
$\tau$ & 0.94 & $D_{\text {ri }}$ & $66 \mathrm{~mm}$ \\
$T_{\text {sun }}$ & $5770 \mathrm{~K}$ & $D_{\text {ro }}$ & $70 \mathrm{~mm}$ \\
$T_{\text {am }}$ & $293 \mathrm{~K}$ & $D_{\text {ci }}$ & $120 \mathrm{~mm}$ \\
$h_{\text {out }}$ & $10 \mathrm{~W} / \mathrm{m}^{2} \mathrm{~K}$ & $D_{\text {co }}$ & $125 \mathrm{~mm}$ \\
\hline
\end{tabular}
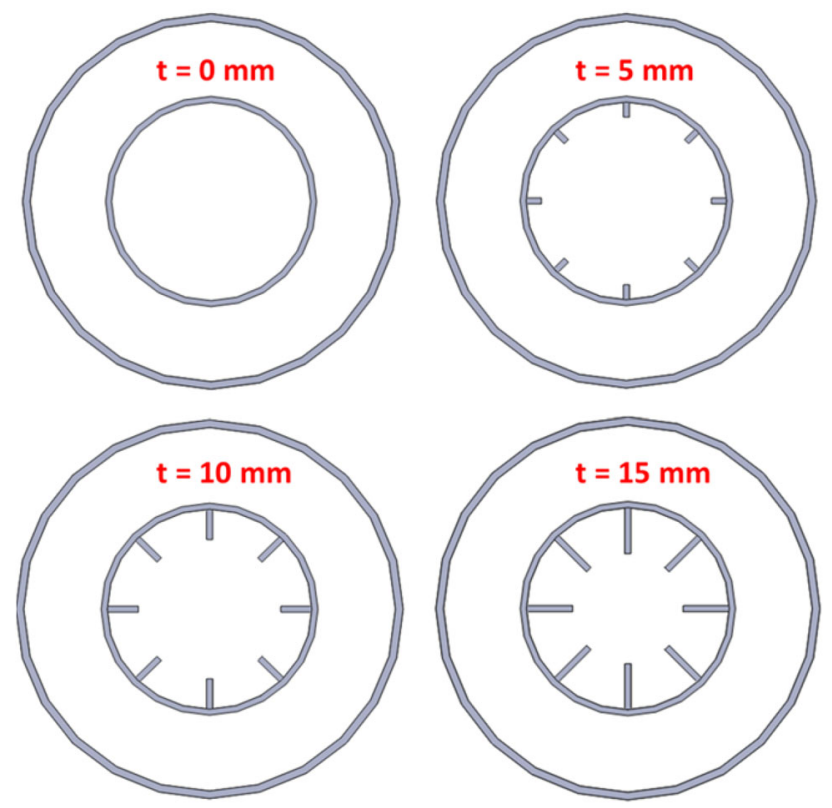

Fig. 2 The examined absorbers with and without internal fins

The available solar beam irradiation in the collector module is the product of its aperture area $\left(A_{\mathrm{a}}\right)$ and of the direct beam solar irradiation $\left(G_{\mathrm{b}}\right)$, as Eq. 1 shows [7, 9]:

$Q_{\mathrm{s}}=A_{\mathrm{a}} \cdot G_{\mathrm{b}}$.

The useful heat $\left(Q_{\mathrm{u}}\right)$ that the carbon dioxide absorbs can be calculated by the energy balance in the fluid volume according to Eq. 2 [7, 9]:

$Q_{\mathrm{u}}=m \cdot c_{\mathrm{p}} \cdot\left(T_{\text {out }}-T_{\text {in }}\right)$.

The thermal efficiency of the solar collector $\left(\eta_{\mathrm{th}}\right)$ is the ratio of the useful thermal energy $\left(Q_{\mathrm{u}}\right)$ to the available solar energy $\left(Q_{\mathrm{s}}\right)$, as Eq. 3 indicates [7, 9]:

$\eta_{\mathrm{th}}=\frac{Q_{\mathrm{u}}}{Q_{\mathrm{s}}}$.

The useful exergetic output of the solar collector $\left(E_{\mathrm{u}}\right)$ can be calculated according to Eq. 4, for ideal gas [23].
This index takes into account the irreversibilities due to the fluid temperature increase, as well as due the pressure losses along the absorber tube. It is important to state that the $\mathrm{R}$ constant for the carbon dioxide is taken equal to $188.95 \mathrm{~J} / \mathrm{kg} \mathrm{K}$.

$E_{\mathrm{u}}=Q_{\mathrm{u}}-m \cdot c_{\mathrm{p}} \cdot T_{\mathrm{am}} \cdot \ln \left[\frac{T_{\text {out }}}{T_{\mathrm{in}}}\right]+R \cdot T_{\mathrm{am}} \cdot \ln \left[\frac{P_{\text {out }}}{P_{\text {in }}}\right]$.

The exergy flow of the undiluted solar irradiation $\left(E_{\mathrm{s}}\right)$ is estimated by the Petela equation [24] which is the most accepted model for calculating this parameter. Equation 5 gives the solar exergy flow definition, with the sun temperature $\left(T_{\text {sun }}\right)$ to be taken equal to $5770 \mathrm{~K}$ [24].

$E_{\mathrm{s}}=Q_{\mathrm{s}} \cdot\left[1-\frac{4}{3} \cdot\left(\frac{T_{\mathrm{am}}}{T_{\mathrm{sun}}}\right)+\frac{1}{3} \cdot\left(\frac{T_{\mathrm{am}}}{T_{\mathrm{sun}}}\right)^{4}\right]$.

The exergetic efficiency $\left(\eta_{\mathrm{ex}}\right)$ is defined as the fluid exergetic output $\left(E_{\mathrm{u}}\right)$ to the available solar irradiation $\left(E_{\mathrm{s}}\right)$, as Eq. 6 presents [9]:

$\eta_{\mathrm{ex}}=\frac{E_{\mathrm{u}}}{E_{\mathrm{s}}}$.

This index expresses how close the system is to the ideal. High values of the exergetic performance indicate low irreversibilities, while low exergetic performance is a result of high entropy generation in the process.

\section{Analysis in Solidworks Flow Simulation}

The simulation tool in this analysis is the commercial software Solidworks Flow Simulation. This software has been used in the simulation of solar collectors [7, 25-29], as well as in other simulation studies [30-34]. In Solidworks Flow Simulation environment, the proper boundary conditions, radiation surfaces, mesh, convergence goals and materials as well as working fluids have to be defined. Additionally, the solar irradiation intensity and the ambient conditions are inserted in the model. The following points summarize the way that the model has been developed.

(a) Boundary conditions

- Inlet temperature level of the carbon dioxide.

- Mass flow rate of the carbon dioxide.

- Static pressure in the outlet of the tube.

- Heat convection coefficient between outer cover surface and ambient.

(b) Materials and fluids

- Carbon dioxide is selected as the only working fluid.

- The parabolic reflector is a mirror surface with reflectance $(r)$ equal to 0.93 . 
Table 2 Validation results for the gas working fluids

\begin{tabular}{|c|c|c|c|c|c|c|c|c|}
\hline \multirow[t]{2}{*}{ Fluid } & \multicolumn{3}{|c|}{ Input data } & \multicolumn{2}{|c|}{ Literature [12] } & \multicolumn{2}{|c|}{ Present model } & \multirow{2}{*}{$\begin{array}{l}\text { Deviation of } \\
\left(T_{\text {out }}-T_{\text {in }}\right)(\%)\end{array}$} \\
\hline & $m(\mathrm{~kg} / \mathrm{s})$ & $T_{\text {in }}(\mathrm{K})$ & $G_{\mathrm{b}}\left(\mathrm{W} / \mathrm{m}^{2}\right)$ & $T_{\text {out }}(\mathrm{K})$ & $\left(T_{\text {out }}-T_{\text {in }}\right)(\mathrm{K})$ & $T_{\text {out }}(\mathrm{K})$ & $\left(T_{\text {out }}-T_{\text {in }}\right)(\mathrm{K})$ & \\
\hline \multirow[t]{3}{*}{$\mathrm{CO}_{2}$} & 0.93 & 498 & 900 & 798 & 300 & 801.2 & 303.2 & 1.067 \\
\hline & 1.1 & 498 & 900 & 778 & 280 & 784.4 & 286.4 & 2.286 \\
\hline & 1.42 & 458 & 900 & 673 & 215 & 678.1 & 220.1 & 2.372 \\
\hline
\end{tabular}

- Glass is the material for the cover and its transmittance $(\tau)$ is selected to be 0.94 , while its emittance $\left(\varepsilon_{\mathrm{c}}\right)$ to be 0.88 .

- The selective absorber is selected to be made of stainless steel. Its absorbance $(\alpha)$ and its emittance $\left(\varepsilon_{\mathrm{r}}\right)$ are selected to be 0.92 and 0.095 , respectively.

(c) Radiation surfaces

Inner and outer cover surfaces are selected to be transparent to solar irradiation in order to let the solar energy reach the absorber.

Absorber outer surface is a selective surface with low emittance and sufficient absorbance.

The reflector surface is selected to be "symmetrical in radiation" to reflect the radiation.

(d) Convergence goals and outputs

- Mean receiver temperature on its outer surface.

- Mean cover temperature in its volume.

- Carbon dioxide bulk temperature at the outlet of the tube.

- Pressure losses along the tube (inlet pressure minus outlet pressure).

(e) Computational domain mesh

Solidworks Flow Simulation creates mesh in the entire computational domain which includes the evacuated tube and the reflector. Refinements are made in the fluid cells inside the tube and in the partial cells between solid and fluid domains. This technique leads to more reliable results because the mesh is denser in the critical regions. After a simple sensitive analysis, 2 million cells are selected as the most appropriate solution for the mesh in order to achieve the proper convergence with a reasonable computational time.

(f) Simulation methodology

The next step after the model development is to run it. Different combinations of the mass flow rates and the inlet temperatures are tested in order to perform a detailed parametric analysis. Four values for the mass flow rate are selected: $0.10,0.15,0.20$ and $0.25 \mathrm{~kg} / \mathrm{s}$. For every mass flow rate, 12 different inlet temperature levels are selected to be tested from 50 to $600{ }^{\circ} \mathrm{C}$ with step equal to $50 \mathrm{~K}$. In every case, the outlet temperature of the carbon dioxide is the most important parameter for the thermal performance calculations. Moreover, the pressure losses along the tube are demanded for the exergetic evaluation of the system. The heat transfer coefficient is estimated using the mean fluid temperature $\left(T_{\mathrm{fm}}\right)$ and the mean absorber temperature $\left(T_{\mathrm{r}}\right)$, as Eq. 7 shows $[7,9]$ :

$h=\frac{Q_{\mathrm{u}}}{\left(\pi \cdot D_{\mathrm{ri}} \cdot L\right) \cdot\left(T_{\mathrm{r}}-T_{\mathrm{fm}}\right)}$.

It is essential to state that the mean fluid temperature is estimated according to the following equation $[7,9]$ :

$T_{\text {fm }}=\frac{T_{\text {in }}+T_{\text {out }}}{2}$.

\section{Validation of the results}

The results of the developed model for the case without internal fins are compared with other literature results. The results of the study in Ref. [12] are selected where the same PTC and carbon dioxide have been used. Table 2 includes the comparison results and finally a deviation of $1-2 \%$ is observed. This result shows that the developed model is accurate and its results are accepted.

\section{Results}

In this section the results of the present study are given. Section "Mass flow rate investigation" is devoted to the mass flow rate investigation of the collector for various temperature levels, while section "Internal fin length investigation" includes the results for the impact of internal fins on the system performance. At the end of this section, the results are discussed in the section "Discussion of the results" with more details.

\section{Mass flow rate investigation}

In this subsection, a parametric analysis with the mass flow rate of carbon dioxide is performed to determine its optimum value. Figures $3,4,5,6,7$, and 8 show the results from this parametric analysis for four different mass flow rate values $(0.10,0.15,0.20$ and $0.25 \mathrm{~kg} / \mathrm{s})$. It is important 
Fig. 3 Thermal performance for various mass flow rates without internal fins

Fig. 4 Exergetic performance for various mass flow rates without internal fins

Fig. 5 Pressure losses for various mass flow rates without internal fins
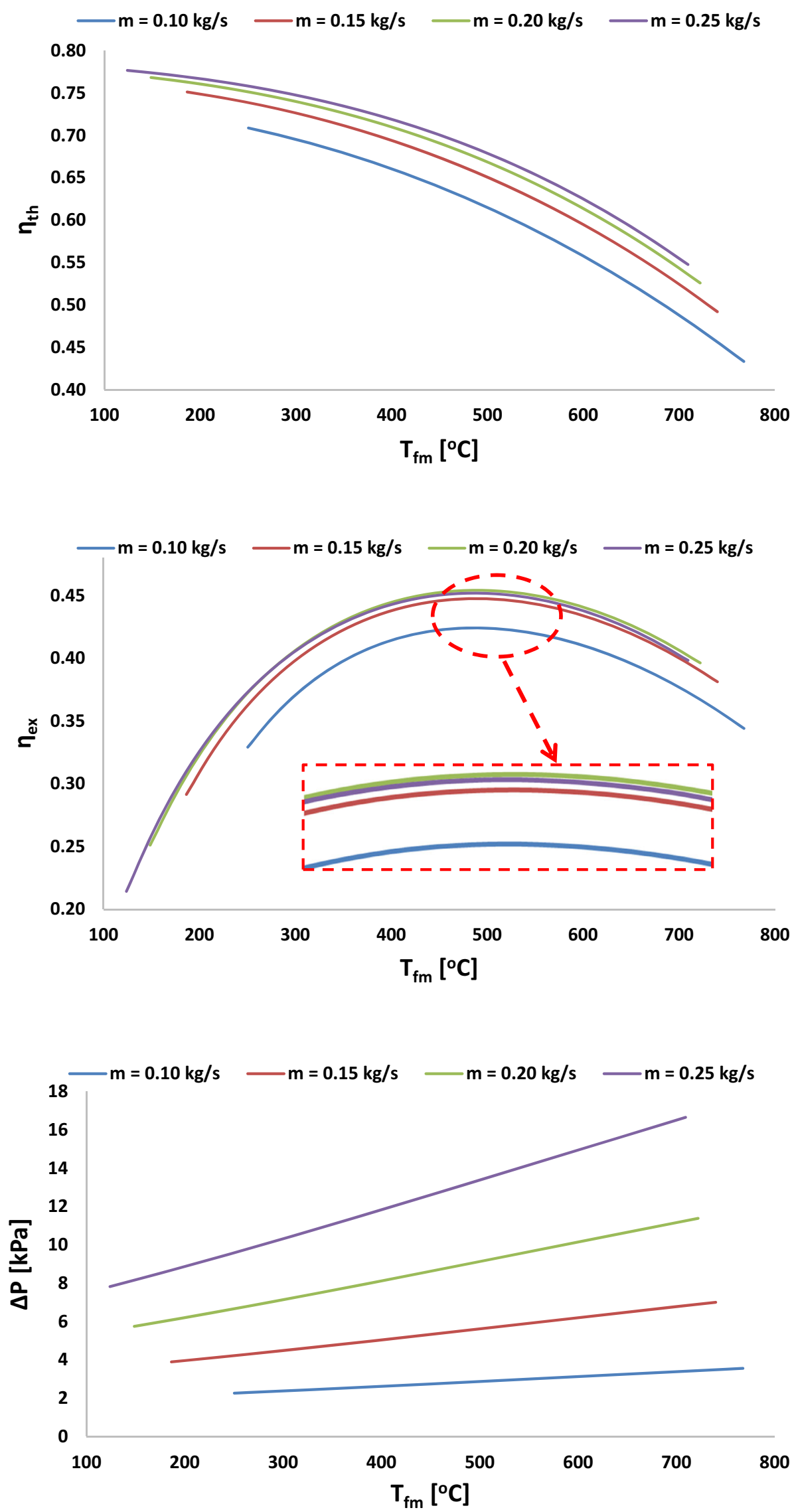
Fig. 6 Heat transfer coefficient for various mass flow rates without internal fins

Fig. 7 Mean absorber temperature for various mass flow rates without internal fins

Fig. 8 Mean cover temperature for various mass flow rates without internal fins
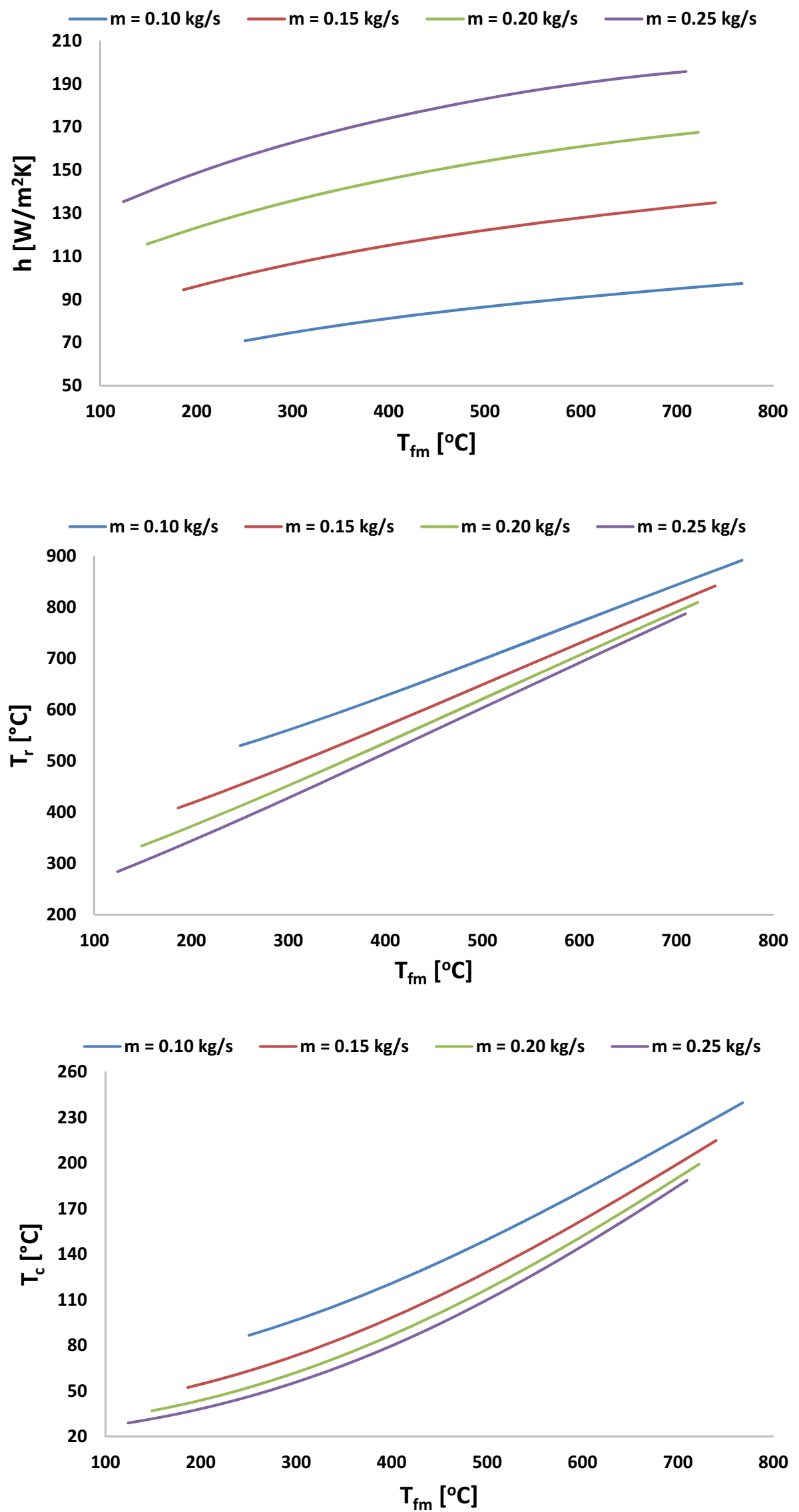
to state that the smooth absorber case is examined in this parametric analysis.

Figure 3 illustrates the thermal performance of the solar collector for the examined mass flow rates and for various mean fluid temperature levels. It is obvious that higher mass flow rate leads to greater thermal efficiency. More specifically, the difference between the curves is getting lower when the mass flow rate increases and, thus, the mass flow rates of 0.20 and $0.25 \mathrm{~kg} / \mathrm{s}$ are the best candidates according to the results of Fig. 3 .

Figure 4 exhibits the exergetic performance of the collector for the examined mass flow rates. All the curves of Fig. 4 have similar shape and they maximized for an intermediate temperature level. The curves for mass flow rates $0.15,0.20$ and $0.25 \mathrm{~kg} / \mathrm{s}$ seem to be close to each other. By observing better the magnified region, the optimum mass flow rate exergetically is $0.20 \mathrm{~kg} / \mathrm{s}$ and this value is selected as the most appropriate. This value leads also to a high thermal efficiency, as it has been discussed in the previous analysis of Fig. 3. In this case, the maximum exergetic performance of the collector is $45.41 \%$ and it is a bit greater than in the other cases.

It is essential to state that higher mass flow rate leads to higher thermal efficiency but simultaneously to higher pressure losses; two contrary factors for the exergetic performance of the collector. Figure 5 shows the pressure losses among the examined cases. It is obvious that the pressure losses increase with the increase in the operating temperature level and with the mass flow rate. Moreover, it is noticeable that the distance between the curves of Fig. 5 is greater for higher mass flow rates. This observation makes clearer the reason for finding that the optimum mass flow rate exergetically is not so high.
Figure 6 depicts the heat transfer coefficient for the examined mass flow rates. The curves seem to be parallel to each other and the mass flow rate increase is beneficial for the heat transfer. Generally, the values of the heat transfer coefficient are relatively low compared to the respective for operation with liquid working fluids. This result is acceptable because the gas working fluids as carbon dioxide have to operate in low mass flow rates, something with negative impact on the heat transfer coefficient. The higher values of this parameter lead to lower mean absorber temperature and to lower cover mean temperature, as it is obvious from Figs. 7 and 8, respectively. More specifically, higher heat transfer coefficient leads to easier heat transfer from the absorber to the fluid and so the absorber can be less warm for higher mass flow rates. Lower temperature levels in the absorber lead to lower thermal losses and so the thermal efficiency of the collector is getting greater. As it is obvious, the results of the Figs. 3, 5 and 6 are in accordance and the results are accepted. Furthermore, the cover temperature is depended on the thermal losses and it follows the temperature levels of the absorber temperature, as it is also proved by Fig. 8 .

\section{Internal fin length investigation}

In this subsection, the impact of internal fins in the performance of the parabolic trough collector is presented. For all the cases, the optimum mass flow rate $(0.20 \mathrm{~kg} / \mathrm{s})$ is selected to be used in order for a suitable comparison to be presented.

Figure 9 exhibits the thermal performance of the collector for the examined cases. More specifically, the smooth absorber $(t=0 \mathrm{~mm})$ is compared with the three
Fig. 9 Thermal performance for optimum mass flow rate and for various internal fin lengths

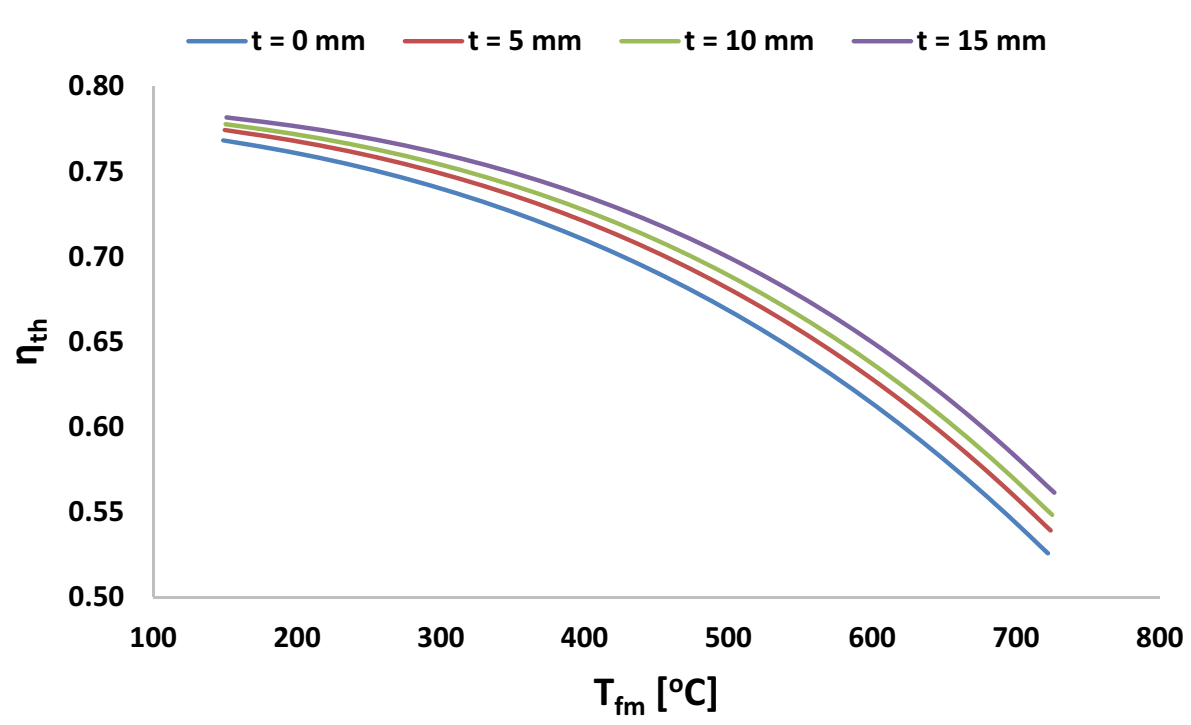


Fig. 10 Heat transfer coefficient for optimum mass flow rate and for various internal fin lengths
Fig. 11 Mean absorber temperature for optimum mass flow rate and for various internal fin lengths
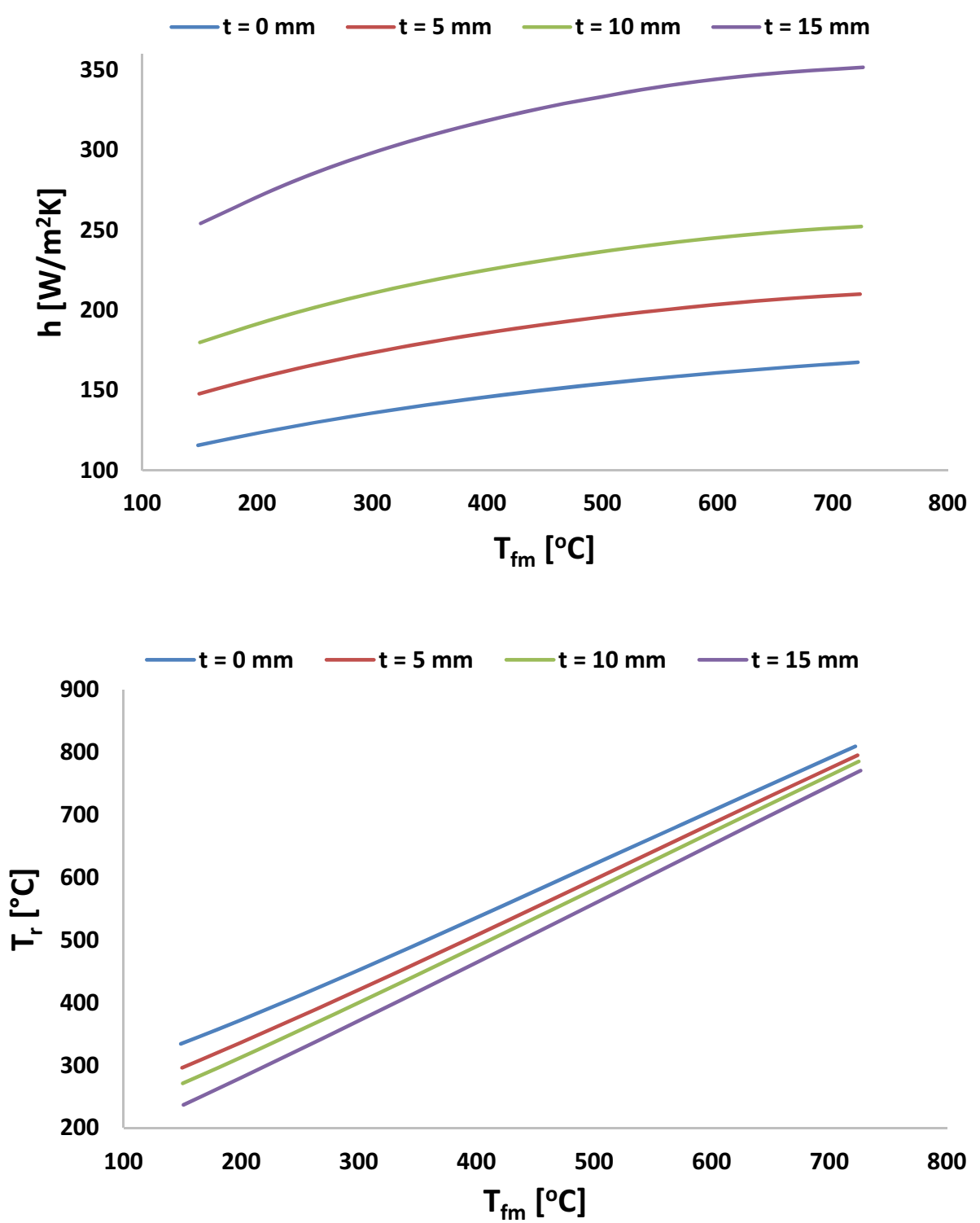

other finned absorbers. Finally it is proved that the existence of fins enhances the performance of the collector and more specifically higher fin length leads to higher thermal efficiency. This result is reasonable, because the existence of fins leads to higher mixing conditions inside the flow. Thus the heat transfer coefficient is enhanced as Fig. 10 shows and the mean receiver temperature is getting lower (Fig. 11). Consequently, the mean cover temperature follows the absorber temperature and it is getting lower for higher fin length (Fig. 12).

Figure 13 shows the exergetic performance of the collector for the examined absorber cases. All the curves seem to be close to each other but the curve which corresponds to $10 \mathrm{~mm}$ fin length leads to the maximum exergetic performance. More specifically, $45.95 \%$ exergetic efficiency can be achieved in this case, while $45.86,45.54$ and $45.40 \%$ can be taken for 5,15 and $0 \mathrm{~mm}$ cases respectively. The existence of optimum fin length for an intermediate value is a result of the contrary impact of the fin length on the thermal efficiency (Fig. 9) and on the pressure losses (Fig. 14). More specifically, Fig. 14 proves that higher fin length leads to greater pressure losses. Especially the difference between the curves of $10 \mathrm{~mm}$ and $15 \mathrm{~mm}$ is higher than the other curve distances. This result can explain the reason for the lower exergetic performance for the $15 \mathrm{~mm}$ case, compared to the $10 \mathrm{~mm}$ case although the thermal efficiency for $15 \mathrm{~mm}$ is the maximum.

Figures 15, 16 and 17 show the temperature distribution of the carbon dioxide in a cross section in the middle of the tube for inlet temperature equal to 300,400 and $600{ }^{\circ} \mathrm{C}$. In every figure among them, there are four subfigures, one for every absorber case. Generally it is obvious that the fluid is 
Fig. 12 Mean cover temperature for optimum mass flow rate and for various internal fin lengths

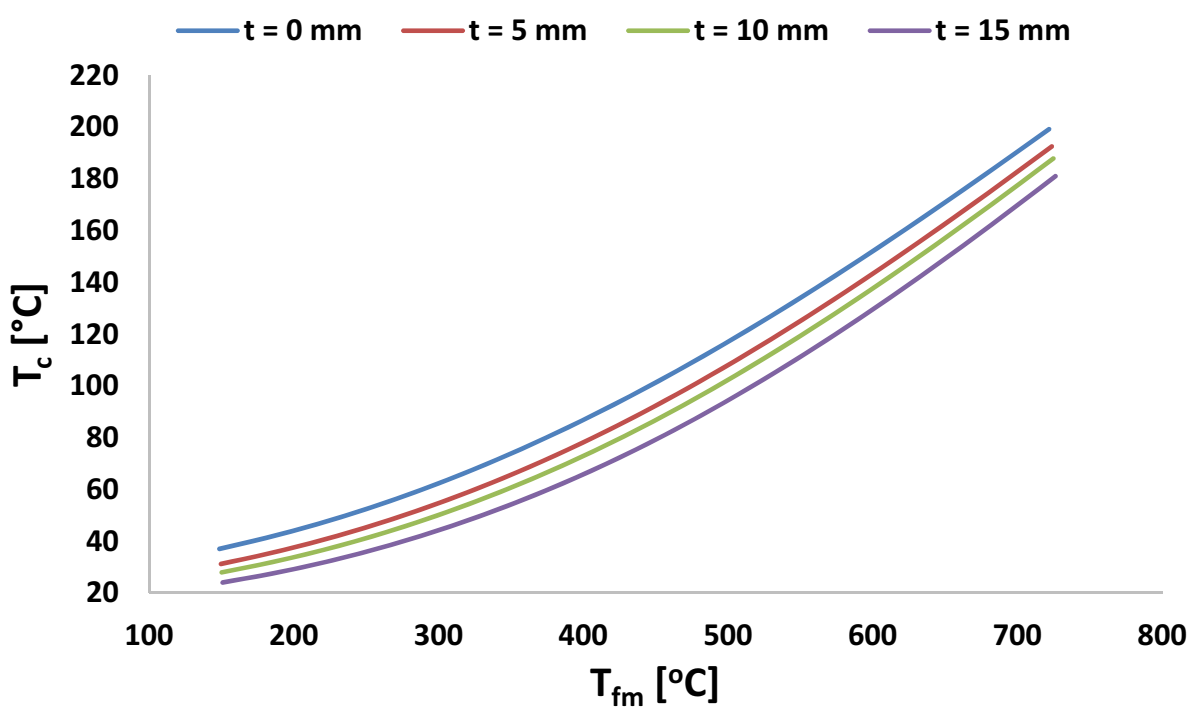

Fig. 13 Exergetic performance for optimum mass flow rate and for various internal fin lengths

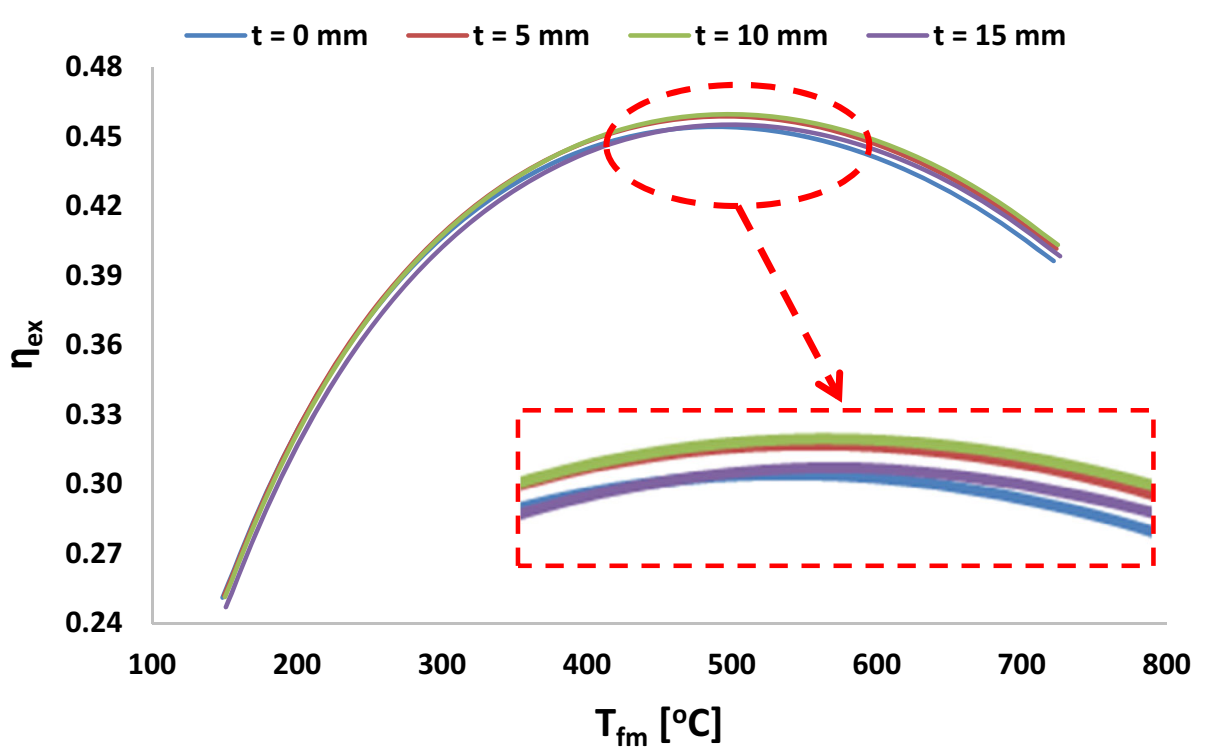

colder in the central core and in the upper part of the tube and it is warmer in the lower part and closer to the tube. The reason for this result is the concentration of the solar irradiation in the low part of the absorber. Moreover, it is obvious that the existence of internal fins removes the warm region in the upper part of the tube, something that enhances the performance of the collector, as it has been stated before.

\section{Discussion of the results}

This work examines the impact of mass flow rate and of the internal fins in the performance of the parabolic trough collectors operating with carbon dioxide. The results of this study are interesting and they can lead to useful conclusions. More specifically, it is interesting that there is optimum mass flow rate and optimum fin length. Mass flow rate equal to $0.20 \mathrm{~kg} / \mathrm{s}$ and fins of $10 \mathrm{~mm}$ length can lead to global maximum in exergetic performance which is equal to $45.95 \%$. In this case, the inlet temperature of the gas in the tube is equal to $400{ }^{\circ} \mathrm{C}$ and the mean fluid temperature is close to $497^{\circ} \mathrm{C}$. This temperature level leads to maximum exergetic performance for all the examined absorber types. This result comes in accordance with the results of Ref. [9] and so it is proved that the PTC with carbon dioxide has to operate in applications with similar temperature levels, as the $400{ }^{\circ} \mathrm{C}$ in the inlet of the tube. 
Fig. 14 Pressure losses for optimum mass flow rate and for various internal fin lengths

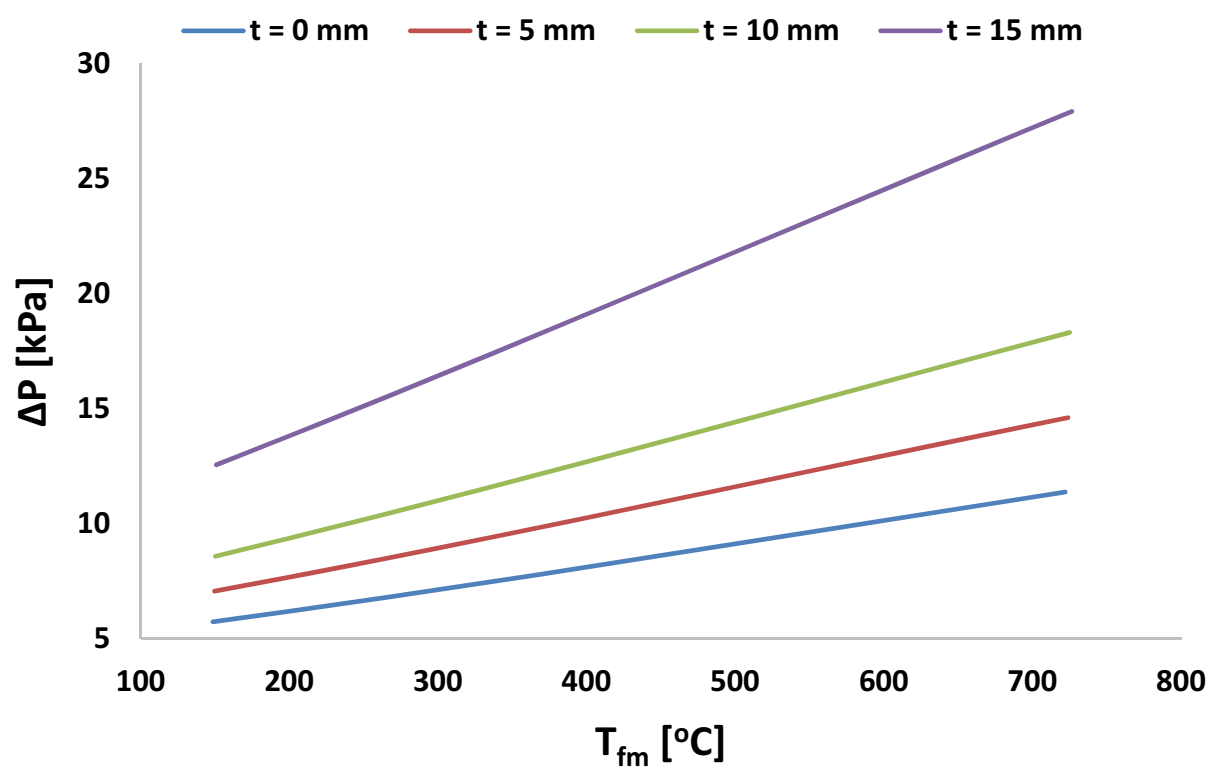

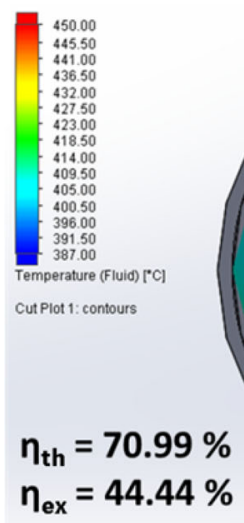
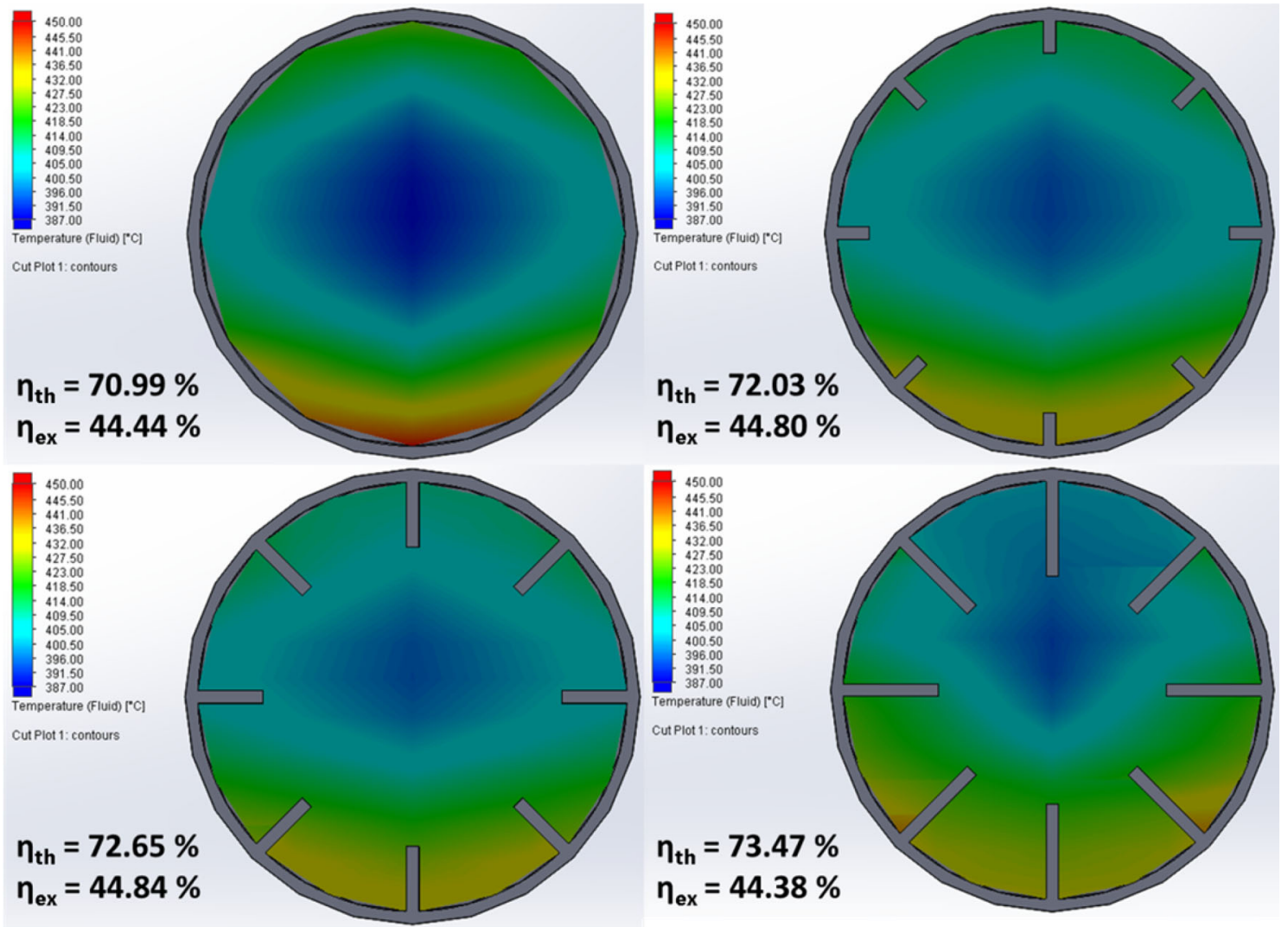

Fig. 15 Middle cross sections for inlet temperature equal to $300{ }^{\circ} \mathrm{C}$ (the temperature levels vary from 387 to $450{ }^{\circ} \mathrm{C}$ )

Table 3 includes the energetic and exergetic results of the four examined absorbers when the mass flow rate is equal to $0.20 \mathrm{~kg} / \mathrm{s}$ (optimum value). It is obvious that there is important thermal enhancement with the use of internal fins which is similar for all the operational temperature levels. More specifically, the use of 5,10 and $15 \mathrm{~mm}$ leads 


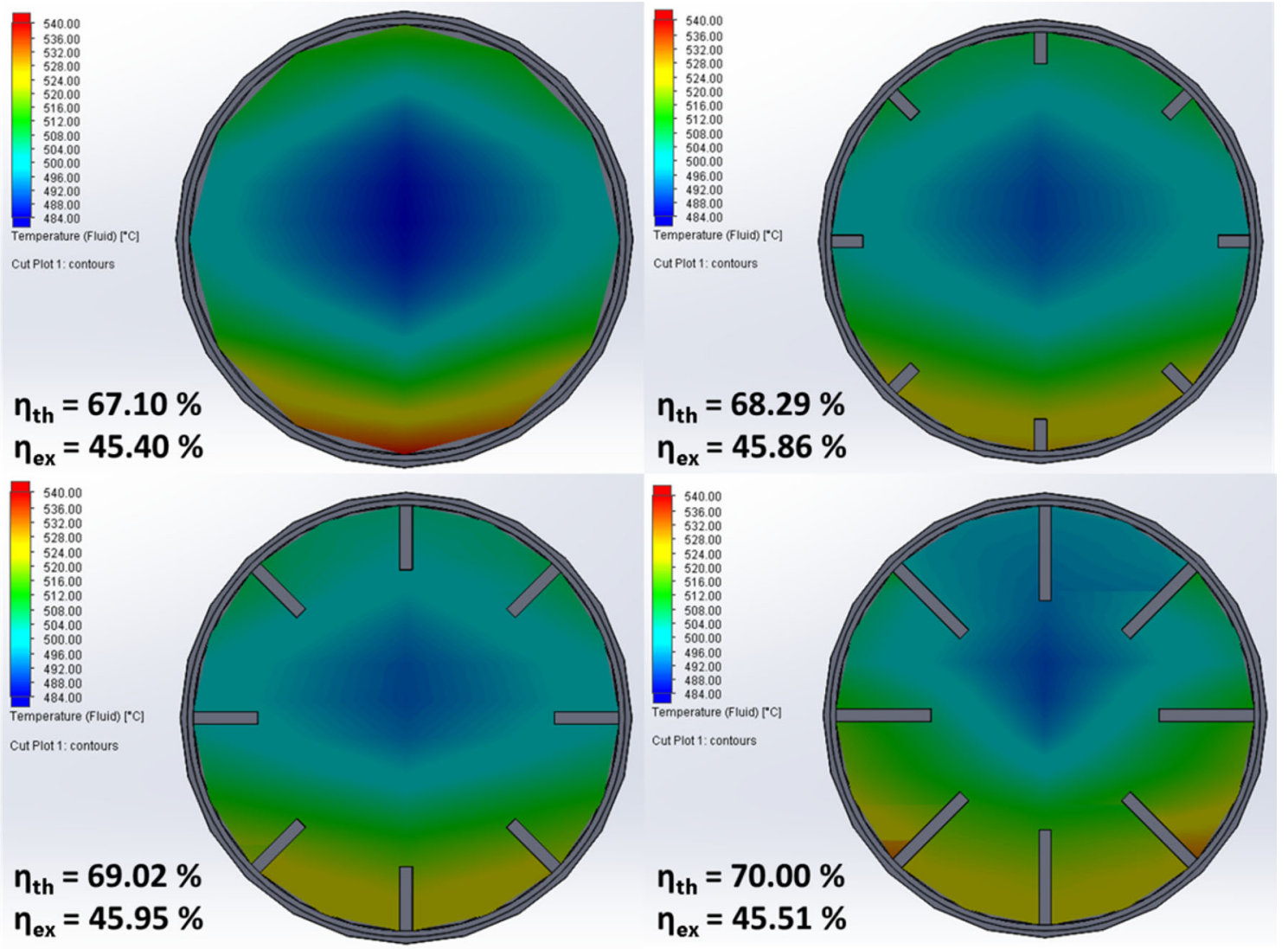

Fig. 16 Middle cross sections for inlet temperature equal to $400{ }^{\circ} \mathrm{C}$ (the temperature levels vary from 484 to $540{ }^{\circ} \mathrm{C}$ )

to mean enhancement, compared to the smooth absorber (0 mm), equal to $1.60,2.60$ and $3.95 \%$, respectively. On the other hand, the exergetic performance is similar among the examined absorbers especially close to the optimum temperature levels. This result can be explained by the increasing rate of the pressure drop for higher fin lengths. Greater fin length creates greater obstacles in the flow and the pressure losses are higher due to the greater friction. The optimum fin length is equal to $10 \mathrm{~mm}$, an important result which indicates that the greater length is not always beneficial in the exergetic performance of the collector. Thus, in any new design with fins, the system has to be designed carefully by taking into account the pressure drop along the tube, especially for operation with gas working fluids.

\section{Conclusions}

In this study, the use of carbon dioxide in a commercial parabolic trough collector (Eurotrough ET-150) is examined for various absorber geometries. More specifically, the smooth absorber is compared with the absorber with internal longitudinal fins. Three different fins of 5, 10 and $15 \mathrm{~mm}$ are examined for a broad range of operation temperature levels.

In the first part of the analysis, the mass flow rate investigation for the smooth absorber is performed. Finally it is proved that the optimum mass flow rate is equal to $0.20 \mathrm{~kg} / \mathrm{s}$. Higher mass flow rates lead to greater thermal performance but also to higher pressure losses. These two contrary factors lead to the existence of the optimum in an intermediate mass flow rate among the examined.

In the investigation of the internal fins in the collector performance, the optimum mass flow rate case is examined. Finally, it is proved that the existence of fins can enhance the performance of the collector by 1.60, 2.60 and $3.95 \%$ for the fin lengths 5,10 and $15 \mathrm{~mm}$ respectively. On the other hand, greater fin length leads to higher pressure drop along the tube and this result counterbalances the thermal enhancement. However, the global maximum is found for the $10 \mathrm{~mm}$ case and for operation close to $500{ }^{\circ} \mathrm{C}$ (mean temperature level). In this case, the exergetic 


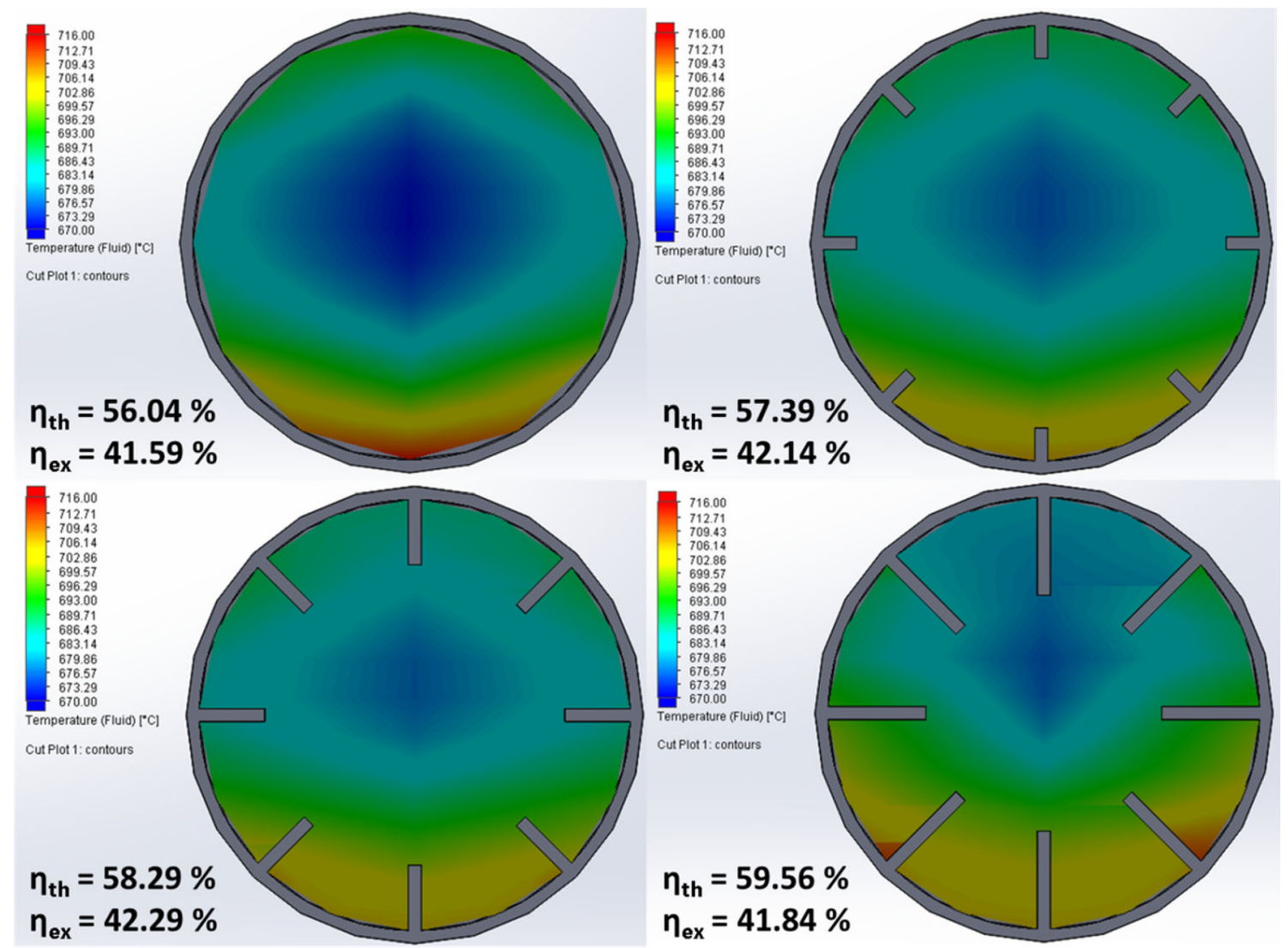

Fig. 17 Middle cross sections for inlet temperature equal to $600{ }^{\circ} \mathrm{C}$ (the temperature levels vary from 670 to $716{ }^{\circ} \mathrm{C}$ )

Table 3 Energetic and exergetic comparison for the examined fin cases with mass flow rate equal to $0.20 \mathrm{~kg} / \mathrm{s}$

\begin{tabular}{|c|c|c|c|c|c|c|c|c|}
\hline \multirow{2}{*}{$T_{\text {in }}\left({ }^{\circ} \mathrm{C}\right)$} & \multicolumn{4}{|l|}{$\eta_{\text {th }}$} & \multicolumn{4}{|l|}{$\eta_{\mathrm{ex}}$} \\
\hline & $t=0 \mathrm{~mm}$ & $t=5 \mathrm{~mm}$ & $t=10 \mathrm{~mm}$ & $t=15 \mathrm{~mm}$ & $t=0 \mathrm{~mm}$ & $t=5 \mathrm{~mm}$ & $t=10 \mathrm{~mm}$ & $t=15 \mathrm{~mm}$ \\
\hline 50 & 0.7639 & 0.7704 & 0.7741 & 0.7785 & 0.2971 & 0.2983 & 0.2977 & 0.2932 \\
\hline 100 & 0.7559 & 0.7632 & 0.7673 & 0.7725 & 0.3499 & 0.3667 & 0.3661 & 0.3460 \\
\hline 150 & 0.7463 & 0.7544 & 0.7590 & 0.7649 & 0.3894 & 0.3915 & 0.3912 & 0.3866 \\
\hline 200 & 0.7387 & 0.7473 & 0.7524 & 0.7588 & 0.4088 & 0.4113 & 0.4112 & 0.4066 \\
\hline 250 & 0.7206 & 0.7303 & 0.7362 & 0.7438 & 0.4359 & 0.4390 & 0.4393 & 0.4346 \\
\hline 300 & 0.7099 & 0.7203 & 0.7265 & 0.7347 & 0.4444 & 0.4480 & 0.4484 & 0.4438 \\
\hline 350 & 0.6852 & 0.6966 & 0.7036 & 0.7130 & 0.4533 & 0.4575 & 0.4583 & 0.4537 \\
\hline 400 & 0.6710 & 0.6829 & 0.6902 & 0.7002 & 0.4540 & 0.4586 & 0.4595 & 0.4551 \\
\hline 450 & 0.6386 & 0.6513 & 0.6594 & 0.6705 & 0.4489 & 0.4541 & 0.4552 & 0.4507 \\
\hline 500 & 0.6204 & 0.6335 & 0.6418 & 0.6534 & 0.4432 & 0.4485 & 0.4498 & 0.4454 \\
\hline 550 & 0.5919 & 0.6053 & 0.6140 & 0.6262 & 0.4315 & 0.4370 & 0.4385 & 0.4340 \\
\hline 600 & 0.5604 & 0.5739 & 0.5829 & 0.5956 & 0.4159 & 0.4214 & 0.4229 & 0.4184 \\
\hline 650 & 0.5259 & 0.5393 & 0.5484 & 0.5615 & 0.3963 & 0.4016 & 0.4032 & 0.3983 \\
\hline
\end{tabular}

efficiency is equal to $45.95 \%$, a high value which indicates the use of carbon dioxide as a working fluid in high temperature levels.
Open Access This article is distributed under the terms of the Creative Commons Attribution 4.0 International License (http://crea tivecommons.org/licenses/by/4.0/), which permits unrestricted use, distribution, and reproduction in any medium, provided you give 
appropriate credit to the original author(s) and the source, provide a link to the Creative Commons license, and indicate if changes were made.

\section{References}

1. Zagba, L., Khennane, M., Mahamedi, I.H., Oudjana, H.S., Fezzari, A., Bouchakour, A., Terki, N.: A combined simulation and experimental analysis the dynamic performance of a $2 \mathrm{~kW}$ photovoltaic plant installed in the desert environment. Int. J. Energy Environ. Eng. 7, 249-260 (2016)

2. Al Mamum, S., Chowdhury, Z.I., Kaiser, M.S., Islam, M.S.: Techno-financial analysis and design of on-board intelligent-assisting system for a hybrid solar-DEG-powered boat. Int. J. Energy Environ. Eng. 7, 361-376 (2016)

3. Grosu, L., Marin, A., Dobrovicescu, A., Queiros-Conde, D.: Exergy analysis of a solar combined cycle: organic Rankine cycle and absorption cooling system. Int. J. Energy Environ. Eng. 7, 449-459 (2016)

4. Qiu, Y., He, Y.-L., Wu, M., Zheng, Z.-J.: A comprehensive model for optical and thermal characterization of a linear Fresnel solar reflector with a trapezoidal cavity receiver. Renew Energy 97, 129-144 (2016)

5. Napoleon, E., Awb, H., Yoshino, H.: Application of renewable energy sources and new building technologies for the Philippine single family detached house. Int. J. Energy Environ. Eng. 6, 267-294 (2015)

6. Bellos, E., Tzivanidis, C., Moschos, K., Antonopoulos, K.A.: Energetic and financial evaluation of solar assisted heat pump space heating systems. Energy Convers. Manag. 120, 306-319 (2016)

7. Tzivanidis, C., Bellos, E., Korres, D., Antonopoulos, K.A., Mitsopoulos, G.: Thermal and optical efficiency investigation of a parabolic trough collector. Case Stud. Therm. Eng. 6, 226-237 (2016)

8. Fernández-García, A., Zarza, E., Valenzuela, L., Pérez, M.: Parabolic-trough solar collectors and their applications. Renew. Sustain. Energy Rev. 14(7), 1695-1721 (2010)

9. Bellos, E., Tzivanidis, C., Antonopoulos, K.A., Daniil, I.: The use of gas working fluids in parabolic trough collectors-an energetic and exergetic analysis. Appl. Therm. Eng. 109, 1-14 (2016)

10. Cipollone, R., Cinocca, A., Gualtieri, A.: Gases as working fluid in parabolic trough CSP plants. Proc. Comput. Sci. 19, 702-711 (2013)

11. Islam, M.K., Hasanuzzaman, M., Rahim, N.A.: Modelling and analysis of the effect of different parameters on a parabolictrough concentrating solar system. RSC Adv. 5(46), 36540-36546 (2015)

12. Muñoz-Anton, J., Biencinto, M., Zarza, E., Díez, L.E.: Theoretical basis and experimental facility for parabolic trough collectors at high temperature using gas as heat transfer fluid. Appl. Energy 135, 373-381 (2014)

13. Al-Sulaiman, F.A., Atif, M.: Performance comparison of different supercritical carbon dioxide Brayton cycles integrated with a solar power tower. Energy 85, 61-71 (2015)

14. Coco-Enríquez, L., Muñoz-Antón, J., Martínez-Val, J.M.: Integration between direct steam generation in linear solar collectors and supercritical carbon dioxide Brayton power cycles. Int. J. Hydrogen Energy 40(44), 15284-15300 (2015)

15. Guo, Z.Y., Li, D.Y., Wang, B.X.: A novel concept for convective heat transfer enhancement. Int. J. Heat Mass Transfer 41, 2221-2225 (1998)
16. Mwesigye, A., Bello-Ochende, T., Meyer, J.P.: Heat transfer and entropy generation in a parabolic trough receiver with wall-detached twisted tape inserts. Int. J. Therm. Sci. 99, 238-257 (2016)

17. Mwesigye, A., Bello-Ochende, T., Meyer, J.P.: Multi-objective and thermodynamic optimisation of a parabolic trough receiver with perforated plate inserts. Appl. Therm. Eng. 77, 42-56 (2015)

18. Şahin, H.M., Baysal, E., Dal, A.R., Şahin, N.: Investigation of heat transfer enhancement in a new type heat exchanger using solar parabolic trough systems. Int. J. Hydrogen Energy 40(44), 15254-15266 (2015)

19. Song, X., Dong, G., Gao, F., Diao, X., Zheng, L., Zhou, F.: A numerical study of parabolic trough receiver with nonuniform heat flux and helical screw-tape inserts. Energy 77, 771-782 (2014)

20. Munoz, J., Abanades, A.: A technical note on application of internally finned tubes in solar parabolic trough absorber pipes. Sol. Energy 85, 609-612 (2011)

21. Kasperski, J., Nemś, M.: Investigation of thermo-hydraulic performance of concentrated solar air-heater with internal multiplefin array. Appl. Therm. Eng. 58(12), 411-419 (2013)

22. Too, Y.C.S., Benito, R.: Enhancing heat transfer in air tubular absorbers for concentrated solar thermal applications. Appl. Therm. Eng. 50(10), 1076-1083 (2013)

23. Bejan, A., Tsatsaronis, G., Moran, M.: Thermal design and optimization. Wiley, New York (1996)

24. Petela, R.: Exergy of undiluted thermal radiation. Sol. Energy 74(6), 469-488 (2003)

25. Tsai, C.Y.: Optimized solar thermal concentrator system based on free-form trough reflector. Sol. Energy 125, 146-160 (2016)

26. Bellos, E., Tzivanidis, C., Antonopoulos, K.A., Gkinis, G.: Thermal enhancement of solar parabolic trough collectors by using nanofluids and converging-diverging absorber tube. Renew. Energy 94, 213-222 (2016)

27. Bellos, E., Korres, D., Tzivanidis, C., Antonopoulos, K.A.: Design, simulation and optimization of a compound parabolic collector. Sustain. Energy Technol. Assess. 16, 53-63 (2016)

28. Bellos, E., Tzivanidis, C., Korres, D., Antonopoulos, K.A.: Thermal analysis of a flat plate collector with Solidworks and determination of convection heat coefficient between water and absorber. In: ECOS Conference, Pau (2015)

29. Bellos, E., Mathioulakis, E., Tzivanidis, C., Belessiotis, V., Antonopoulos, K.A.: Experimental and numerical investigation of a linear Fresnel solar collector with flat plate receiver. Energy Convers. Manag. 130, 44-59 (2016)

30. Ambekar, A.S., Sivakumar, R., Anantharaman, N., Vivekenandan, M.: CFD simulation study of shell and tube heat exchangers with different baffle segment configurations. Appl. Therm. Eng. 108, 999-1007 (2016)

31. Driss, Z., Mlayeh, O., Driss, D., Maaloul, M., Abid, M.S.: Numerical simulation and experimental validation of the turbulent flow around a small incurved Savonius wind rotor. Energy 74, 506-517 (2014)

32. Valančius, K., Motuzienè, V., Paulauskaitè, S.: Redeveloping industrial buildings for residential use: Energy and thermal comfort aspects. Energy Sustain. Dev. 29, 38-46 (2015)

33. Driss, S., Driss, Z., Kammoun, I.K.: Computational study and experimental validation of the heat ventilation in a living room with a solar patio system. Energy Build. 119, 28-40 (2016)

34. Bellos, E., Tzivanidis, C., Zisopoulou, E., Mitsopoulos, G., Antonopoulos, K.A.: An innovative Trombe wall as a passive heating system for a building in Athens-a comparison with the conventional Trombe wall and the insulated wall. Energy Build. 133, 754-769 (2016) 